\title{
Research on "3+4" Consistent and Segmented Training Mode for Second Vocational to Undergraduate in Engineering Majors
}

\author{
Xuehua Jiang, Peijiang Chen \\ School of Automobile, Linyi University, Shandong, 276000, China \\ jxhyx@163.com, chenpeijiang@163.com
}

\begin{abstract}
Keywords: Engineering major; " $3+4$ " seven-year; second Vocational to undergraduate; consistent and segmented
\end{abstract}

\begin{abstract}
The application-oriented universities docks second vocational schools, implementing the " $3+4$ " consistent and segmented training mode for second vocational to undergraduate in engineering majors, building talent training overpass of vocational education. It can provide vocational students the continue learning channel, optimize the educational resources of both fusion vocational education and undergraduate education, enhance their comprehensive quality and ability to adapt to society, enhance the quality of teaching vocational education. It is the extending process of vocational education to the undergraduate higher education, enriching the levels for vocational education, exploring the methods of training practical and professional talents.
\end{abstract}

\section{Introduction}

The economy of China is in a stage of rapid development, a large number of application-oriented talents are needed by companies, which is most appropriate for higher vocational and technical education. It is still a new topic for government and schools how to organize high vocation and technical education of applied talents [1]. In 2022, the Ministry of Education promulgated the "Several opinions on promoting high vocational education reform and innovation and leading scientific development of vocational education". In 2014, the State Council issued the "decisions on developing modern vocational education by the". The government of China puts forward the goals and directions of vocation education development. By 2020, it will form modern vocation education system of adapting to development needs, deep integration of production and teaching, connection of secondary and higher vocational school, communicating between vocational education and general education, reflecting lifelong education concept and having Chinese characteristic. The transformation development emphasis of general undergraduate colleges and universities is proposed. It is to take the way of pilot promotion, demonstration lead, and guide transformation from general universities to applied technology, and focus on organizing undergraduate vocational education.

\section{The Background of “ $3+4$ ” Consistent and Segmented Training}

At present, the homogenization development of higher education in China is serious, resulting in employment difficulties. The applied undergraduate focuses on application, which demands new talent view, quality view and education view reflecting times spirit and social development, so as to construct new discipline direction, specialty structure and curriculum system, train high quality talents with strong social adaption and competition ability. Under the background of higher education reform, some applied universities began to implement new recruitment methods, such as docking vocational school, carrying out consistent training, and expanding school form.

There are three modes of vocational education segment training. The first one is " $3+2$ " segment education mode for secondary vocational to higher vocational, the second one is " $3+2$ " training mode for higher vocational education to undergraduate, and the third one is " $3+4$ " segment training mode for secondary vocational education to undergraduate. The former two modes have been implemented for many years, and the third one has just started to explore. Currently, there are several substantive implemented provinces by the government, such as Jiangsu, Shandong, Guangxi, Shanghai, Hebei, 
Chongqing, an so on, of which the earliest province are Jiangsu and Shandong. Shandong started " $3+4$ " consistent and segmented training pilot in 2013, further expanded the scope of enrollment pilot colleges and professional coverage in 2014, and there had been 34 pilot secondary vocational schools, 17 universities, 18 segment majors, and planned enrollment of 2870 students. By 2015, nearly 10 provinces and cities had began " $3+4$ " consistent and segmented training pilots for secondary vocational education to undergraduate, which declares that the pattern is the development trend of vocational education, getting more and more attention and being put into practice.

\section{The Significance of " $3+4$ " Consistent and Segmented Training}

Be useful for students' innovation and entrepreneurship ability, and adapt to the needs of society for multi-level applied talents

The " $3+4$ " consistent and segmented training mode is an important attempt for modern vocational education system, and it is the convergence of secondary vocational education and traditional undergraduate education. Different from the past talent cultivation goal of secondary vocational education and undergraduate, it is positive improvement of current education system, complying with the reform development direction of high education popularization. It is conductive to clear the status and role of different level vocational education, can rich the channels of talent culture and enhance quality of vocational education institutions.

Be conducive to changing the talents training ideas of applied undergraduate, and promoting professional development features

The specialty setting and talent culture in local applied colleges must be closed to local industry development needs [2]. The local applied undergraduate colleges and universities should meet the needs of the development of local industry, setting up the applied majors scientifically, clearing the aim of educating talents. The local applied undergraduate colleges and universities can break the problems of focusing on theory and ignoring practice by carrying out the new " $3+4$ " consistent and segmented training mode.

Be conducive to complementary advantages of vocational education and general education, and improve the talent training quality of vocational education

In order to build the talent training overpass of vocational education, the two schools can co-operate each other, optimize educational resources on both sides, integrate the education ideas of vocational education and undergraduate education, integrated design teaching programs, curriculum and assessment index system, and innovate training model [3]. On the other hand, the two schools can construct training mode of work-study combination according to the relationship between theoretical and practical training.

\section{The Key Problems of “ $3+4$ ” Consistent and Segmented Training}

\section{Identify the target of “ $3+4$ ” segment cultivation}

In terms of training objectives, the position of " $3+4$ " segment cultivation is employment-oriented, making the competence and professionalism training as the core. It can cultivate undergraduate high-quality technical talents who comprehensively develops in moral, intellectual, physical, and aesthetic aspects, full of innovative spirit and practical ability, systematically masters the basic theory and professional knowledge, has strong professional skills and ability to analyze and solve practical problems, and can meet the needs of jobs related the professional requirements through seven years education of " $3+4$ " consistent and segmented training for second vocational and undergraduate education.

\section{Construct convergence mechanism of " $3+4$ " segment cultivation}

The " $3+4$ " is a new two-stage training model, not simply the degree grafting. Unlike previous vocational counterparts, but according to the seven-year consistent principle, it designs the high-quality technology personnel training objectives, training standards, curriculum, teaching system, assessment criteria, quality assessment standards and other aspects of a comprehensive 
innovation reform. The mode integrates the vocational resources of second vocational schools and universities [4]. Considering the actual situation of the students, it should develop personnel training programs adapting the vocational students, building the teaching system, curriculum, innovative training model for the " $3+4$ " segment cultivation, and training high-level technical talents.

\section{Develop curriculum system of “ $3+4$ ” segment cultivation}

According to the skill requirements of engineering specialty, the teaching content in two phases should be taken into a unified framework, and the curriculum system of theory enough, outstanding skill, segmentation implement will be set. In terms of curriculum system, the course will be set from easy to difficult [5]. The courses in second vocational stage can lay foundation and pay attention to convergence, while the undergraduate courses should focus on combination of practice and theory. The curriculum system setting of vocational stage will strengthen mathematics, physics, English and other basic knowledge teaching, at the same time, professional skills and experiment training teaching will be strengthened, so that students have certain skills and solid professional knowledge, and can adapt to undergraduate theory and higher levels skills learning.

\section{Innovative training methods through education segment}

Carrying out innovative education should take innovative design as an important carrier, and design training methods according to personnel training objectives [6]. The teaching process should combine with the reality, market and enterprise. It should build knowledge innovation system, teaching innovation system, personality innovation system in accordance with professional innovation personality training objective. The experiment teaching mode should be reformed, the open laboratory management practice should be developed, and the instructors should be arranged to guide the research teams.

\section{The Safeguard Measures of “3+4” Consistent and Segmented Training}

\section{Strengthen the teachers construction and improve the ratio of double-certificated teachers}

The teacher training at home and abroad should be actively carried out, promoting the teachers renew education concept to improve the ability of teaching and applied scientific research. The role of basis teaching and research section should be given full play, young teacher tutorial system can be implemented to help young teachers get rapid growth. The exchange and cooperation system of hiring outstanding business enterprise personnel should be developed, promoting the teachers to actively participate in production and technology research to enrich the practical experience. The efforts of double-certificated teachers training and introduction should be increased to meet the needs of applied talents training.

\section{Improve experimental conditions based on personnel training requirements}

In addition to perfecting professional laboratory, it also should set up innovative training labs, virtual simulation labs and academic competitions training labs. The practice teaching should be emphasized. The practice teacher and teaching hours should be ensured. It should create a number of comprehensive, designable and innovative experiments, arrange course design, production practice and graduation practice, emphasize integration of production and teaching, closely cooperate with relevant enterprises, regularly organized students to visit, learn and practice, reform experimental teaching mode, develop management measures of open laboratory, arrange teachers to guide the research team. Meanwhile, according to the thought of segmented vocational skill training and obtaining professional qualification certificates, the students should master the skills requested.

\section{Innovative teaching methods according to the integration of production and education}

The education mode should establish the management and operation mechanism of division of individual responsibility for the " $3+4$ " consistent and segmented training research. It can carry out the reform of teaching methods, actively implement integration teaching of learning-by-doing, and try flipped classroom teaching and other new ways, to promote teaching reform of goal-oriented, task-driven, and combination of theory and practice. The training pattern of theory learning, 
engineering design ability, engineer training, and capacity certificate examination should be constructed.

\section{Use a variety of assessment methods and reform academic evaluation methods}

It should weaken summative evaluation and promote formative assessment. In the course examination results, the proportion of school assignment, periodic tests, interim results, experimental and actual operating performance should be increased. The incentive system for getting innovative credits should be formulated, including scientific research, extracurricular practice, academic competitions and paper publication. It should comprehensively assess students' ability and quality, and truly reflect the training level of application ability.

\section{Conclusions}

The " $3+4$ " consistent and segmented training mode for second vocational to undergraduate is a new thing, it can realize complementary education, cohesion education and association education between second vocational and undergraduate. It can provide a new way to access higher education, and provide a rising channel of improving their comprehensive vocational ability and strengthen vocational development for the secondary school students. At the same time, it also provides a new training model of good hands-on ability and good theoretical basis for university. Currently, the model is still in the pilot exploration stage, so the government should promote top-down system reform from secondary vocational to undergraduate, to provide policy security for the convergence. The secondary vocational schools and local application-oriented colleges should also emancipate the mind, strengthen close cooperation, realize education concept change, and promote the development of the vocational education.

\section{Acknowledgment}

This work was supported by the Teaching Reform Research Project of Undergraduate College of Shandong, China (No. 2015M060).

\section{References}

[1] Z. H. Liu, X. J. Hu, Design of Integration Couse for " $3+4$ " Vocational and Undergraduate Segment Cultivation, Vocational and Technical Education. 35(17) (2014) 29-32.

[2] Y. Zhang, Vocational Education Integration Research Based on "3+4" Model, Journal of Shandong Institute of Commerce and Technology. 14(1) (2014) 51-53.

[3] X. H. Jiang, Some Thinking and Practice on Innovation and Entrepreneurship of Engineering Specialty, Journal of Linyi University. 37(6) (2015) 106-111.

[4] G. Y. Li, Y. M. Yang, An Analysis of “3+3” Training in Stages: A Case Study, Jiangsu Education Research. (3) (2014) 78-80.

[5] Y. Y. Hou, Garment Specialty Secondary and Undergraduate Course “3+4” Model Segmentation Cultivation and Cohesion, Journal of Jimusi Vocational Institute. (4) (2015) 2-3.

[6] Z. L. Sun, Research into the "3+2" Stage Training of Financial Management Professionals of Higher Vocational Majors and Application - Oriented Graduates, Journal of Xinyu University. 19(5) (2014) 137-139. 